\title{
SPINAL DEFORMITIES IN NEUROFIBROMATOSIS
}

\author{
J. W. Laws and C. Pallis, London, England \\ From the Departments of Radiodiagnosis and Medicine (Neurology') \\ Postgraduate Medical School, London
}

\begin{abstract}
About 50 per cent of patients with neurofibromatosis show skeletal abnormalities (Hunt and Pugh 1961). Although any bone may be affected the spine is involved in a high proportion of cases. Neurilemmomata and neurofibromata of the spinal nerves, and very occasionally tumours arising from the paravertebral sympathetic chain, may cause local erosion of the vertebrae.

The radiological demonstration of wide intervertebral foramina or scalloped vertebral bodies in a patient with neurofibromatosis naturally raises the possibility of a pressure effect of this kind. In a proportion of cases such tumours may indeed be the cause of the vertebral abnormalities, but it is insufficiently recognised that similar bony changes may occur in neurofibromatosis in the absence of a local tumour. Such " dysplasic " (non-erosive) disorders of bone are sometimes associated with small meningoceles.

Most reviews of large series of patients with neurofibromatosis stress the " erosive " bony changes and imply that erosion by tumours is the most common cause of the spinal abnormalities. For example, Crowe, Schull and Neel (1956) reviewed 227 patients with neurofibromatosis and described the vertebral changes in some detail. Indentation of the borders of vertebral bodies was attributed to "soft-tissue tumours lying within or in close proximity to involved bone." In a study specifically devoted to the bone changes in neurofibromatosis Levene (1959) stated that the abnormalities of the vertebral bodies are " due to pressure from adjacent neurofibromata." He made no reference to spinal meningoceles or to the possibility that the vertebral deformities might be dysplasic in origin.

Other authors (Hunt and Pugh 1961) recognise that some of the spinal changes in neurofibromatosis may be part of the mesodermal dysplasia that is now considered to be a basic component of the disease. Referring to the scoliosis so commonly seen they state that neurofibromata, although they may contribute to the abnormality, cannot fully account for it, in view of " their inconstant presence and their limited distribution compared with the extent of the vertebral deformity." Nevertheless, they imply that scalloping of vertebral bodies is always the result of erosion, caused by neurogenic tumours. It is interesting, however, that as far back as 1950 Inglis mentioned wedging of vertebrae in neurofibromatosis and stated that at necropsy these might not be associated with recognisable neurofibromatous tissue in or near to the deformed vertebrae.

The occurrence of spinal meningoceles in patients with neurofibromatosis has been previously reported (Pohl 1933, Nanson 1957, Sammons and Thomas 1959, Zacks 1960). Raison (1956) summarised all the previously reported cases. However, the association of meningoceles with enlarged intervertebral foramina and other vertebral deformities has seldom received comment. We think it important that this association should be better known, so that patients with neurofibromatosis and certain patterns of spinal deformity should be spared unnecessary investigations or operation. This paper reports an attempt to assess the significance of certain spinal changes in neurofibromatosis.
\end{abstract}

\section{CLINICAL MATERIAL}

Eighteen unselected patients with neurofibromatosis were examined radiologically, with special reference to the spine. They had attended various departments of Hammersmith Hospital in the course of the last ten years. Clinically these cases fell into four main groups. 
Group 1-Six patients (Cases 1 to 6) had come asking for removal of cutaneous nodules. The offending nodules were excised in each instance and the diagnosis was confirmed by histological examination.

Group 2-One patient (Case 7) had come because of a massive swelling on one side of the neck which was found to be caused by sarcomatous change in a neurofibroma.

Group 3-Six patients (Cases 8 to 13) had been admitted to hospital for various medical, surgical or gynaecological disorders. Neurofibromatosis was obvious in each case but was not the presenting complaint.

Group 4-Five patients (Cases 14 to 18) had come with neurological symptoms. All had obvious neurofibromatosis. Two were mentally retarded children, a third had suffered from seizures since adolescence, a fourth presented with " tension" headaches and a fifth (Case 18) had a spastic paraplegia of rather unusual type.

Spinal abnormalities were encountered in all groups. No abnormal neurological signs could be elicited in the patients in Groups 1 to 3, although in several cases there were quite marked spinal deformities. The neurological features in the patients in Group 4 were not considered to be related to the abnormalities found on radiography of the spine. The following case histories illustrate some of the problems encountered.

\section{CASE REPORTS}

\section{VERTEBRAL BODY SCALLOPING NOT CAUSED BY EROSION BY TUMOUR}

Case 7-A girl of seventeen, an apprentice bookbinder, was admitted to hospital in January 1959. She had had a lump in the left side of her neck for as long as she could remember. The mass had recently started to enlarge and the overlying skin had become tender.

Examination revealed a large, firm, lobulated mass in the left posterior triangle extending up to the mastoid and disappearing anteriorly behind the sternomastoid, inferiorly behind the clavicle and posteriorly behind the trapezius. Scanty subcutaneous nodules were seen elsewhere. There were two large café-au-lait patches over the back. There were no abnormal neurological signs.

Operation-At operation the whole mass was dissected free. It weighed 190 grammes and had involved the supraclavicular nerves but not the brachial plexus. Histological examination showed a plexiform neurofibroma without evidence of malignancy.

Progress-The patient was readmitted six months later because of the appearance of a hard mass in the left supraclavicular region. She was two months pregnant. Dilated veins were seen over the anterior chest wall and over the upper part of the left arm. A drill biopsy showed no obvious sarcomatous degeneration. She was given a course of radiotherapy $(5,000$ rads on the linear accelerator, over a period of four weeks). Radiographs of the spine at this stage (Fig. 1) showed a concavity of the right lateral border of the twelfth thoracic vertebral body with a deformity of the adjacent posterior end of the right twelfth rib. Lateral views showed a typical "capstan" deformity of the eleventh and twelfth thoracic vertebral bodies. She remained well for a few months. In January 1961 she was delivered of a healthy female infant. In the next few weeks she became increasingly dyspnoeic and developed a dull pain in the left arm, which gradually became swollen. She was found to have multiple "cannon-ball" secondary deposits in the lungs. There were still no abnormal neurological signs. She died in August 1961.

Necropsy revealed a neurofibrosarcoma arising in the left supraclavicular region and invading the left breast and pleura. There were massive secondaries in the lungs and bilateral pleural effusions. The left axillary vein was thrombosed. Careful dissection of the spine, in the region of the abnormal vertebral bodies, revealed no extraspinal neurofibroma or plexiform neuroma. There was no meningocele.

VOL. 45 B, NO. 4, NOVEMBER 1963 


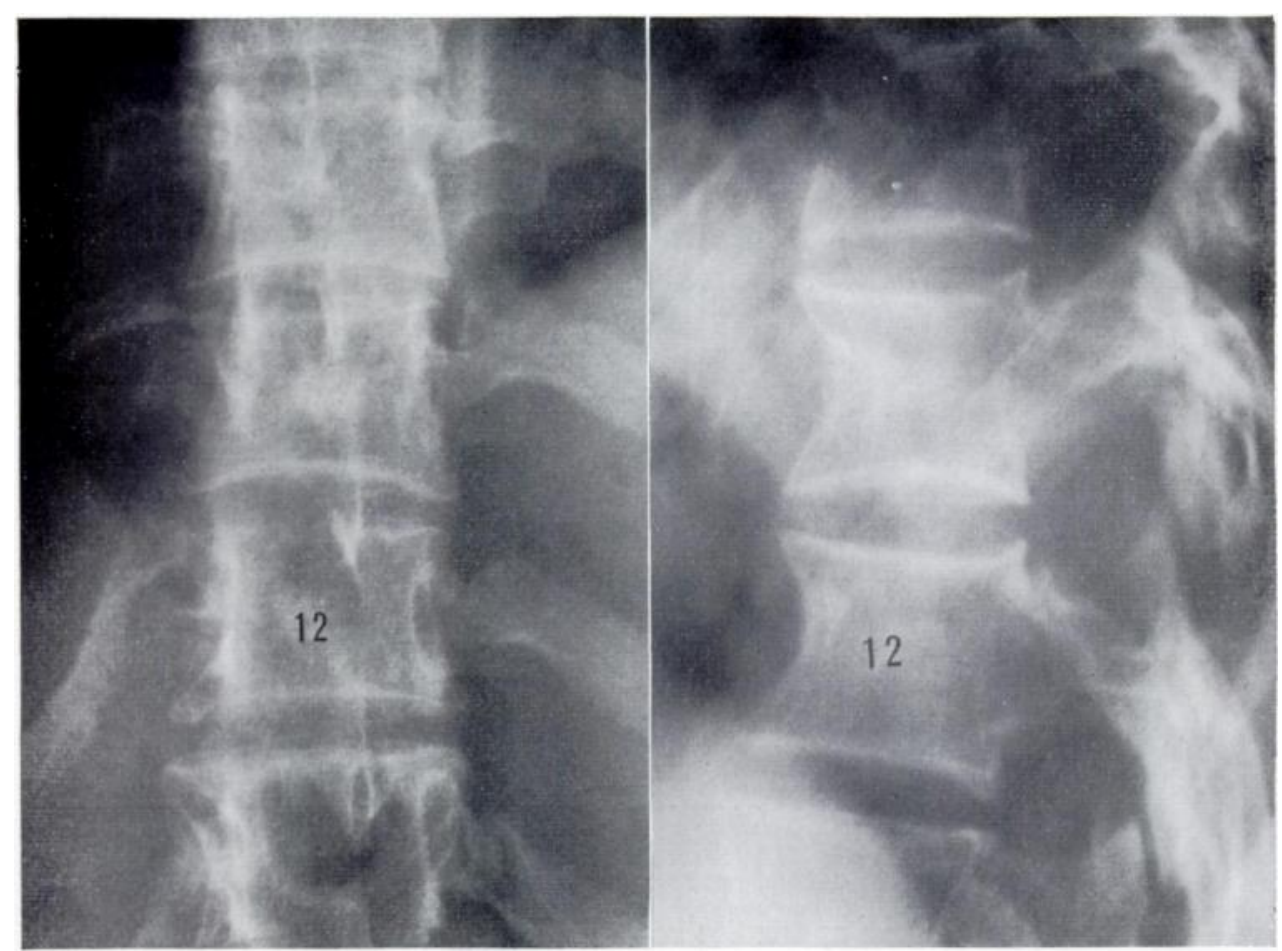

FiG. 1

Case 7-Anterior vertebral scalloping not caused by tumour erosion. Note in the antero-posterior view the concavity of the right border of the twelfth thoracic vertebra with deformity of the adjacent posterior end of the twelfth right rib. The lateral view shows "capstan " deformity of the eleventh and twelfth theracic vertebrae. This patient died from a sarcoma and at necropsy no soft-tissue abnormality was found in this region: in particular there was no evidence of a local neurofibroma.

FORAMINAL ENLARGEMENT NOT CAUSED BY “DUMB-BELL” TUMOUR

Case 10-A woman of twenty-nine developed severe pre-eclamptic toxaemia in February 1960 during the seventh month of her first pregnancy. She was later delivered of a macerated foetus. She was admitted to hospital in January 1961 for investigation of episodic hypertension, presenting as headache and periodic blurring of vision. On examination there was generalised neurofibromatosis. The blood pressure fluctuated between $140 / 90$ and 200/120 millimetres of mercury. There were no abnormal cardiac, retinal or neurological signs. Renal function was normal. An extensive biochemical and radiological search, including aortography and presacral oxygen insufflation and tomography, failed to reveal evidence of phaeochromocytoma.

Radiographs of the thoracic spine showed " reversed wedging" of the fourth thoracic vertebra (Fig. 2). Antero-posterior radiographs of the lower thoracic and upper lumbar spine showed deformities of the eleventh and twelfth thoracic and the first and second lumbar vertebrae, more marked on the left (Fig. 3). The left pedicles were flattened and there were deformities of the posterior ends of the eleventh and twelfth ribs. The intervertebral foramina between the eleventh and twelfth thoracic and the first and second lumbar vertebrae appeared enlarged.

Lateral tomographs (Fig. 4) showed typical "capstan" deformities of the eleventh and twelfth thoracic and first lumbar vertebrae from concavity of the anterior and posterior vertebral margins.

Lumbar puncture yielded cerebrospinal fluid with a protein content of 47 milligrams per 100 millilitres. There was no manometric block. Myelography was performed with the patient recumbent with the left side down and with a horizontal ray. Small meningoceles were 


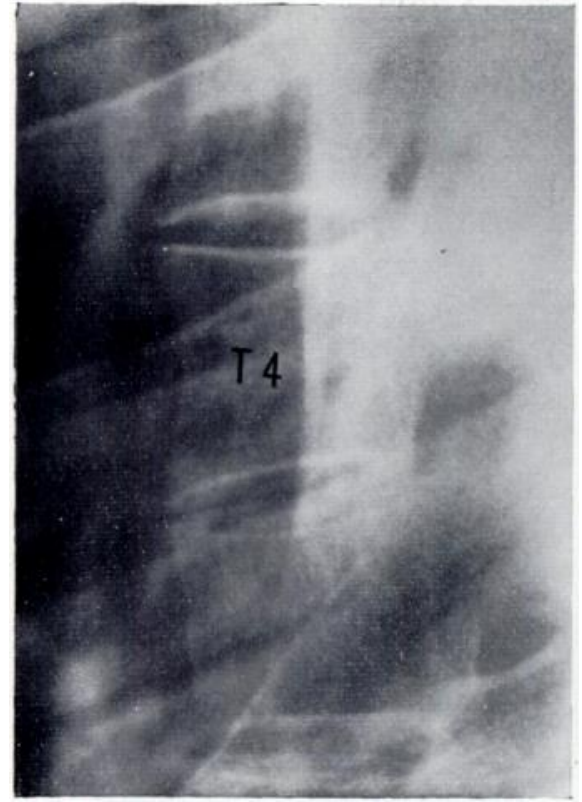

FIG. 2

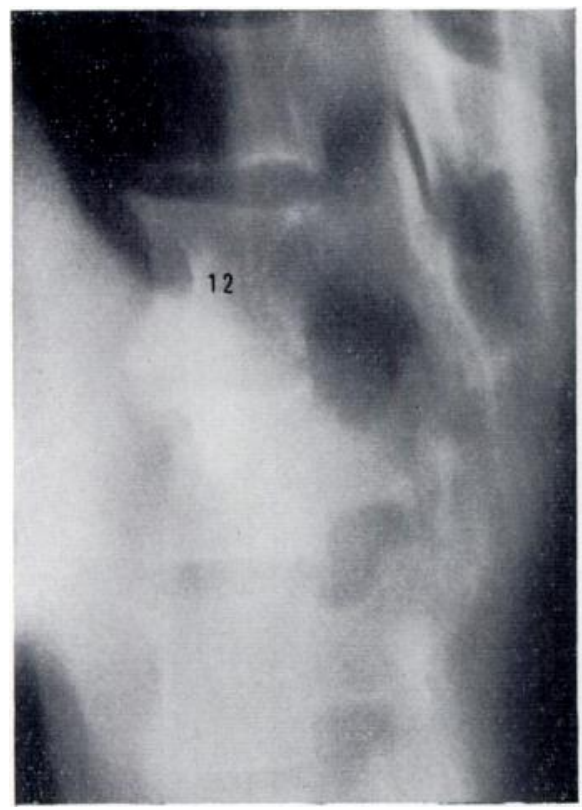

Fig. 4

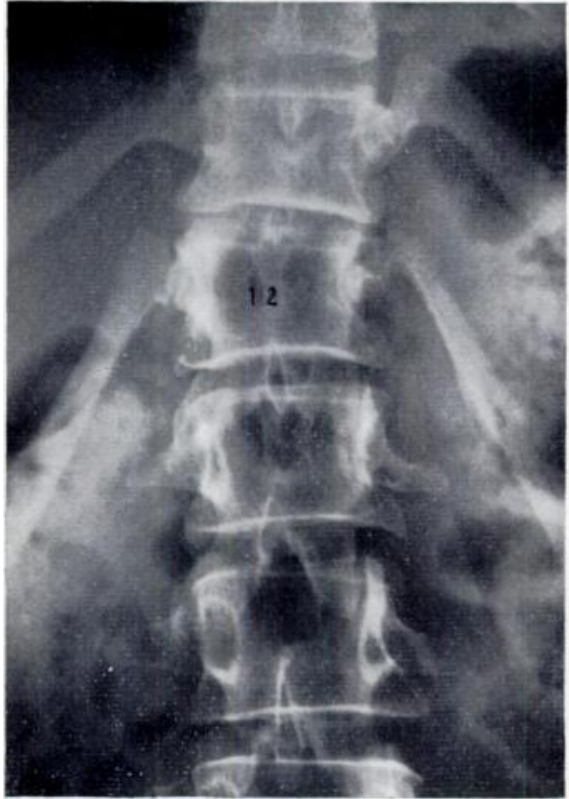

FIG. 3

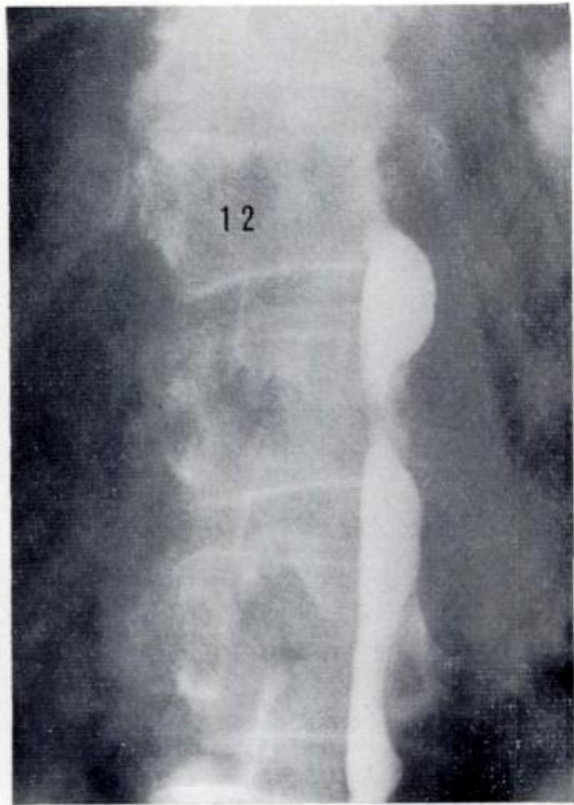

FIG. 5

Case 10-Enlarged intervertebral foramen not caused by dumb-bell tumour. Figure 2-Lateral radiograph shows " reversed wedging " of the fourth thoracic vertebral body. Figure 3Antero-posterior radiograph shows deformity of the eleventh and twelfth thoracic and first and second lumbar vertebral bodies, more marked on the left side than on the right. There is also some deformity of the posterior ends of the eleventh and twelfth left ribs. The left pedicles of the twelfth thoracic and first lumbar vertebrae are flattened. Figure 4-Lateral tomograph shows "capstan" deformity of the eleventh and twelfth thoracic and first lumbar vertebral bodies produced by concavity of the anterior and posterior margins. Note the enlargement of intervertebral foramina, especially that between the twelfth thoracic and first lumbar vertebrae. Figure 5-Myelograph with the patient recumbent, left side down, and with a horizontal ray. Note the small meningoceles between the twelfth thoracic and first and second lumbar vertebrae. 
demonstrated (Fig. 5) between the twelfth thoracic and first lumbar and between the first and second lumbar vertebrae.

\section{PARAVERTEBRAL OPACITY NOT CAUSED BY “DUMB-BELL" TUMOUR}

Case 13-A forty-nine-year-old machine operator had suffered from a productive cough for eleven weeks. Miniature radiography performed in March 1957 revealed a large circumscribed opacity in the upper part of the left lung field. He was referred to Hammersmith Hospital.

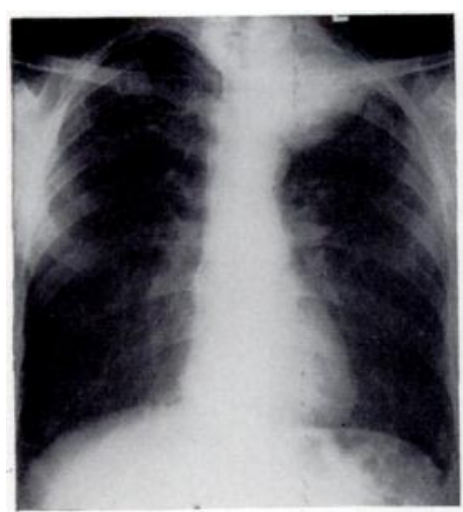

Fig. 6

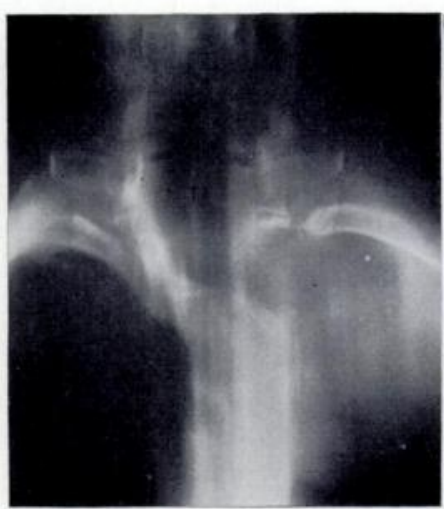

FIG. 7

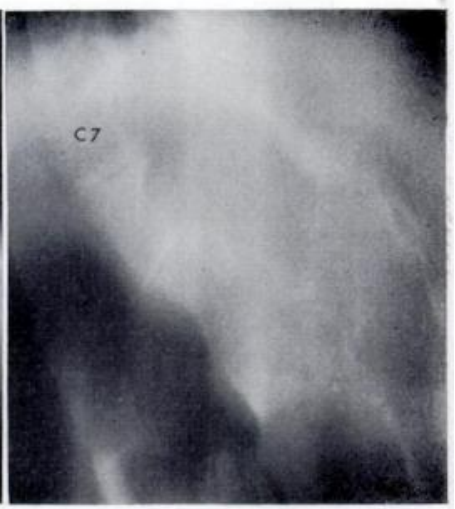

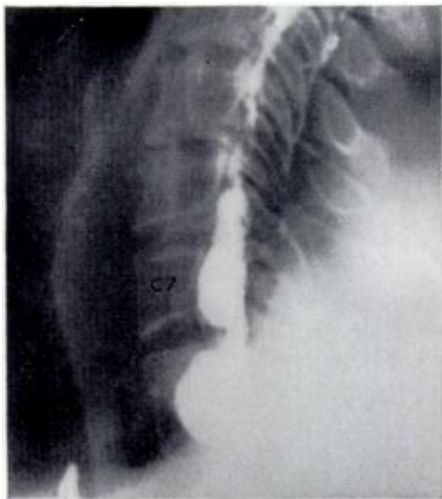

FIG. 8

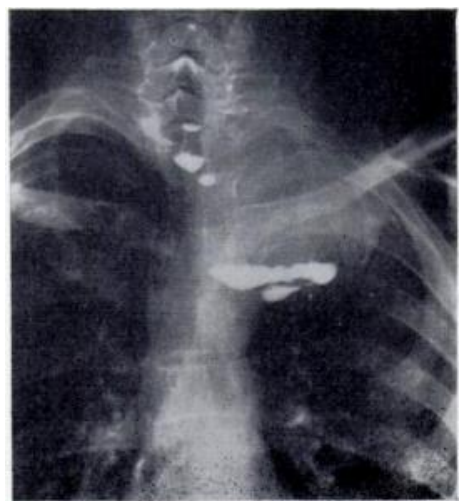

FIG. 9

Case 13-Thoracic meningocele in neurofibromatosis. Figure 6-Postero-anterior radiograph showing a circumscribed soft-tissue mass occupying the upper part of the left hemithorax. Figure 7-Anterior tomograph showing destruction of the left pedicle of the first and second thoracic vertebrae with deformity of the vertebral bodies. Lateral tomograph showing the concavity of the posterior margins of the sixth and seventh cervical and first and second thoracic vertebrae. Figure 8-Lateral myelograph showing contrast filling the defects in the posterior aspect of the bodies of the seventh cervical and first thoracic vertebrae. Figure 9-Myelograph with patient standing. Contrast is seen in the bottom of the large thoracic meningocele and also in a number of smaller meningoceles in the lower cervical and upper thoracic region.

He was a small, pigeon-chested man with generalised neurofibromatosis. There were scanty physical signs of consolidation at the left apex but no abnormal neurological signs.

Postero-anterior radiographs of the chest showed a circumscribed soft-tissue mass occupying the upper part of the left hemithorax (Fig. 6). Anterior tomography of the lower cervical and upper thoracic spine (Fig. 7) showed destruction of the left pedicles of the first and second thoracic vertebrae with deformity of the vertebral bodies. Lateral tomography (Fig. 7) of the same region showed concavity of the posterior margins of the sixth and seventh cervical and the first and second thoracic vertebrae. 
Lumbar puncture yielded normal cerebrospinal fluid under normal pressure. There was no manometric block. The lateral cervical myelograph showed the contrast filling the defects in the posterior aspects of the bodies of the seventh cervical and first thoracic vertebrae (Fig. 8). The contrast could be made to enter the thoracic "mass." Films taken with the patient standing (Fig. 9) showed the contrast at the bottom of a large thoracic meningocele. They also showed a number of smaller meningoceles in the lower cervical and upper thoracic regions.

SPASTIC PARAPLEGIA UNRELATED TO NEUROFIBROMATOSIS DESPITE PRESENCE OF SMALL MENINGOCELES AT MYELOGRAPHY

Case 18-A widow of sixty-nine was referred to the Neurological Department in April 1958 because of a slowly progressive weakness of the legs associated with precipitancy of micturition. There were no complaints of disturbance of sensibility. There had been no previous episodes of neurological disorder.

She had generalised neurofibromatosis, bilateral cataracts and mild hypertension of 190/100 millimetres of mercury. Cerebration was slow. Examination of the cranial nerves and upper limbs revealed no abnormal signs. There was slight diffuse weakness of the legs with exaggerated knee jerks, rather sluggish ankle jerks and an extensor plantar response on the left. Postural sense was impaired in the toes and vibration sense was depressed at the left ankle. There was slight Rombergism. There was no disturbance of superficial sensibility.

Radiographs of the skull, cervical and thoracic spine showed no abnormality. The electroencephalograph showed a " flat" record with an excess of fast activity. The haemoglobin content was 84 per cent of the standard, and free acid was present in the gastric juice.

The spinal fluid contained 35 milligrams of protein per 100 millilitres and showed no manometric abnormality. A myelograph showed no hold-up of the contrast medium in the cervical or thoracic region but outlined several small meningoceles (Fig. 10). No firm diagnosis was established. The paraplegia was thought to be cerebral in origin and perhaps caused by cortical atrophy but encephalography was not thought justifiable.

Observation was continued for two years. No significant deterioration occurred and the patient died at home of pneumonia. There was no necropsy.

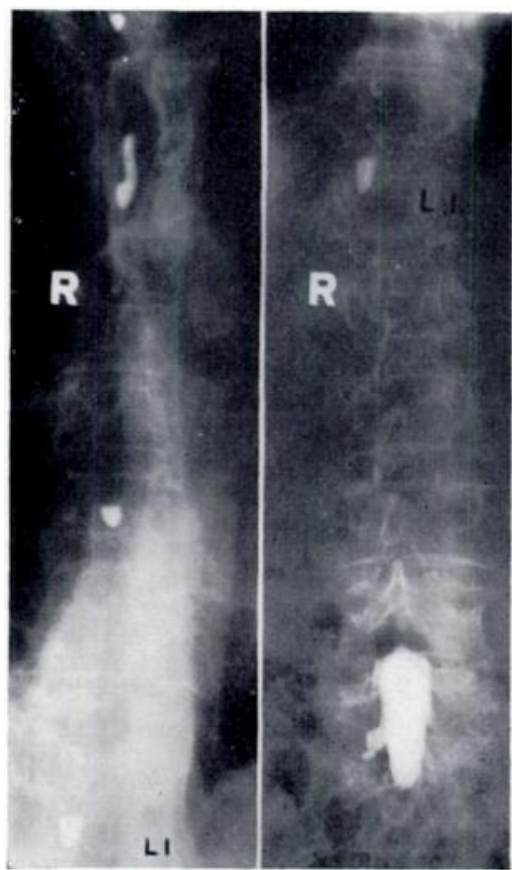

FIG. 10

Case 18-Multiple small meningoceles. No related neurological signs. Myelograph with patient standing showing small meningoceles at the first, fifth and ninth thoracic and the first lumbar vertebral levels.

\section{Plain radiographs}

\section{RADIOLOGICAL FEATURES}

Scoliosis-Scoliosis was noted in seven patients. In six it was accompanied by other abnormalities in the spine but these were not necessarily at the same level. The scoliosis affected the thoracic spine in six cases and the upper lumbar spine in one. None of our patients showed the severe angular scoliosis with dysplasia of the vertebral bodies considered by Hunt and Pugh (1961) to be characteristic of neurofibromatosis.

Deformity of vertebral bodies-An abnormal concavity of vertebral bodies, affecting several adjacent vertebrae, was noted in five patients. Posterior, anterior or lateral aspects of the bodies could be affected. When the posterior and lateral margins were affected the adjacent intervertebral foramen was commonly enlarged (Fig. 4). When the anterior and posterior 
TABLE I

The Incidence of the Various Radiological Abnormalities in Eighteen Patients with Neurofibromatosis

\begin{tabular}{|c|c|c|c|c|c|}
\hline $\begin{array}{c}\text { Case } \\
\text { number }\end{array}$ & $\begin{array}{c}\text { Age } \\
\text { (years) }\end{array}$ & Sex & Scoliosis & Vertebral scalloping & Enlarged foramen \\
\hline 1 & 58 & Female & None & None & None \\
\hline 2 & 28 & Male & None & None & None \\
\hline 3 & 46 & Female & None & $\begin{array}{l}\text { Eleventh and twelfth thoracic } \\
\text { (front and back) }\end{array}$ & None \\
\hline 4 & 37 & Male & Fourth thoracic & None & Second-third cervical (left) \\
\hline 5 & 40 & Female & Eighth thoracic & None & None \\
\hline 6 & 26 & Female & None & None & None \\
\hline 7 & 17 & Female & First lumbar & $\begin{array}{l}\text { Tenth, eleventh and twelfth } \\
\text { thoracic. } \\
\text { First and second lumbar } \\
\text { (front and back). } \\
\text { Twelfth thoracic (right) }\end{array}$ & None \\
\hline 8 & 55 & Male & Fourth thoracic & None & None \\
\hline 9 & 52 & Female & None & None & None \\
\hline 10 & 29 & Female & None & $\begin{array}{l}\text { Eleventh and twelfth thoracic } \\
\text { and first and second lumbar } \\
\text { (front and back and sides) }\end{array}$ & $\begin{array}{c}\text { Twelfth thoracic-first lumbar } \\
\text { (left) }\end{array}$ \\
\hline 11 & 48 & Female & None & None & None \\
\hline 12 & 46 & Male & None & None & None \\
\hline 13 & 49 & Male & None & $\begin{array}{l}\text { Sixth and seventh cervical } \\
\text { and first and second thoracic } \\
\text { (back and sides) }\end{array}$ & $\begin{array}{l}\text { Seventh cervical-first thoracic } \\
\text { (left) }\end{array}$ \\
\hline 14 & 15 & Female & None & None & None \\
\hline 15 & 14 & Female & Seventh thoracic & None & None \\
\hline 16 & 38 & Male & Seventh thoracic & $\begin{array}{l}\text { Second lumbar } \\
\text { (front and back) }\end{array}$ & $\begin{array}{l}\text { Second-third; third-fourth; } \\
\text { fourth-fifth; fifth-sixth } \\
\text { cervical (left) } \\
\text { Second-third; sixth-seventh } \\
\text { cervical (right) }\end{array}$ \\
\hline 17 & 47 & Male & Seventh thoracic & None & None \\
\hline 18 & 69 & Female & None & None & None \\
\hline
\end{tabular}

borders were affected the lateral radiograph showed the "capstan" appearance (Fig. 1). One patient showed deformity of the anterior, posterior and right lateral borders of the eleventh and twelfth thoracic vertebrae with deformity of the posterior end of the right twelfth rib, suggesting local bone erosion (Fig. 1). At necropsy, however, no soft-tissue abnormality was found at this site and the bone structure appeared macroscopically normal. In three other patients similar deformities were shown by myelography to be associated with meningoceles.

One patient had an unusual deformity of the body of the fourth thoracic vertebra which was deeper at the front than at the back (Fig. 2). We have not found any previous reference to this type of " reversed wedging." 
TABLE I-continued

The InCidence of the Various Radiological Abnormalities in Eighteen Patients with Neurofibromatosis

\begin{tabular}{|c|c|c|c|c|}
\hline Pedicle deformity & Rib deformity & Tomography & Myelography & Figure \\
\hline None & None & - & - & - \\
\hline None & None & - & - & - \\
\hline None & None & - & - & - \\
\hline None & None & - & - & - \\
\hline None & None & - & - & - \\
\hline None & None & - & - & - \\
\hline $\begin{array}{l}\text { Eleventh and twelfth } \\
\text { thoracic } \\
\text { (right) }\end{array}$ & $\begin{array}{l}\text { Tenth, eleventh } \\
\text { and twelfth } \\
\text { (right) }\end{array}$ & - & - & 1 \\
\hline None & None & - & - & - \\
\hline None & None & - & - & - \\
\hline $\begin{array}{l}\text { Eleventh and twelfth } \\
\text { thoracic and first lumbar } \\
\text { (left) }\end{array}$ & $\begin{array}{c}\text { Eleventh and twelfth } \\
\text { (left) }\end{array}$ & Yes & $\begin{array}{l}\text { Meningocele. } \\
\text { Twelfth thoracic-first lumbar; } \\
\text { first-second lumbar } \\
\text { (left) }\end{array}$ & $2-5$ \\
\hline None & None & - & - & - \\
\hline None & None & - & - & - \\
\hline $\begin{array}{l}\text { Seventh cervical and } \\
\text { first and second thoracic } \\
\text { (left) }\end{array}$ & None & Yes & $\begin{array}{l}\text { Anterior thoracic } \\
\text { meningocele }\end{array}$ & $6-9$ \\
\hline None & $\begin{array}{l}\text { Third, fourth and fifth } \\
\text { (right) }\end{array}$ & - & - & - \\
\hline None & None & - & - & - \\
\hline None & None & 一 & - & - \\
\hline None & None & - & - & - \\
\hline None & None & - & $\begin{array}{l}\text { Meningocele. } \\
\text { First, fifth and ninth } \\
\text { thoracic and first lumbar }\end{array}$ & 10 \\
\hline
\end{tabular}

Widening of the intervertebral foramina was noted in four patients. In none was there any neurological evidence of a tumour of the spinal nerve. In two patients submitted to myelography the deformity was shown to be associated with a meningocele (Figs. 4 and 5).

In three patients there was evidence of deformity of the pedicles suggesting local erosion. In two of these myelography demonstrated local meningoceles and no evidence of tumour (Figs. 3 to 5). From this it will be seen that even erosion of pedicles, in neurofibromatosis, need not imply a local tumour.

Tomography - Tomography was of considerable value in assessing spinal deformity. Anteroposterior tomographs demonstrated erosion of pedicles (Fig. 7), while lateral tomographs were particularly useful in demonstrating scalloping of vertebral bodies (Figs. 4 and 7).

VOL. 45 B, NO. 4, NOVEMBER 1963 
Myelography-Meningoceles were demonstrated in three patients. In two, myelography was performed in order to exclude a dumb-bell tumour suspected because of enlarged intervertebral foramina and scalloping of the vertebral bodies. There were no neurological symptoms or signs in these patients. This experience has led us to conclude that myelography is probably unnecessary in neurofibromatosis in the absence of clinical symptoms or signs, whatever the radiological appearances of the spine may be.

The incidence of the different abnormalities is shown in Table I.

\section{SUMMARY AND CONCLUSIONS}

1. Neurofibromatosis is a disease involving both neuro-ectodermal tissues and mesodermal elements. In the past it has usually been assumed that the mesodermal abnormalities were secondary to the neuro-ectodermal ones. For example, skeletal deformities were considered to be caused by local neurofibromata.

2. It is becoming increasingly recognised that in neurofibromatosis there may be abnormal development of bone without any local abnormality of neuro-ectodermal origin. Study of our patients confirms this view. Considerable deformity of vertebral bodies was demonstrated at sites where there was no evidence of any neurofibroma or other soft-tissue change. At other sites apparent erosion of bone was associated with the formation of a local meningocele.

3. The findings in this small series of patients with neurofibromatosis suggest that the scalloping of the vertebral bodies, deformity of pedicles and widening of the intervertebral foramina are usually caused by dysplasia of bone and may be associated with a local meningocele.

Since the completion of this study two papers have appeared which reach conclusions similar to our own (Heard, Holt and Naylor 1962; Heard and Payne 1962).

\section{REFERENCES}

Crowe, F. W., Schull, W. J., and Neel, J. V. (1956): A Clinical, Pathological, and Genetic Study of Multiple Neurofibromatosis. Springfield, Illinois: Charles C. Thomas.

Heard, G. E., Holt, J. F., and Naylor, B. (1962): Cervical Vertebral Deformity in von Recklinghausen's Disease of the Nervous System. A Review with Necropsy Findings. Journal of Bone and Joint Surgery, 44-B, 880.

Heard, G., and Payne, E. E. (1962): Scolloping of the Vertebral Bodies in von Recklinghausen's Disease of the Nervous System (Neurofibromatosis). Journal of Neurology, Neurosurgery and Psychiatry, 25, 345.

Hunt, J. C., and Pugh, D. G. (1961): Skeletal Lesions in Neurofibromatosis. Radiology, 76, 1.

INGLIS, K. (1950): The Nature of Neurofibromatosis and Related Lesions. Journal of Pathology and Bacteriology, $62,519$.

Levene, L. J. (1959): Bone Changes in Neurofibromatosis: Report of a Case with Coincidental Osteitis Deformans and Review of the Literature. Archives of Internal Medicine, 103, 570.

Nanson, E. M. (1957): Thoracic Meningocele Associated with Neurofibromatosis. Journal of Thoracic Surgery, 33, 650.

Ронь, R. (1933): Meningokele im Brustraum unter dem Bilde eines intrathorakalen Rundschattens. Röntgenpraxis, 5, 747.

RAISON, J. C. A. (1956): Intrathoracic Meningocele. Thorax, 11, 334.

Sammons, B. P., and Thomas, D. F. (1959): Extensive Lumbar Meningocele Associated with Neurofibromatosis. American Journal of Roentgenology, 81, 1,021.

ZACKs, A. (1960): Atlanto-occipital Fusion, Basilar Impression, and Block Vertebrae Associated with Intraspinal Neurofibroma, Meningocoele, and von Recklinghausen’s Disease. Radiology, 75, 223. 